\title{
Peroxidase, polyphenol oxidase activity and total phenolic concentration in birch (Betula pendula) in vitro shoots during rejuvenation
}

\author{
Elva Girgžde, Ineta Samsone*, Arnis Gailis \\ Latvian State Forest Research Institute “Silava”, Rīgas 111, Salaspils LV-2169, Latvia \\ ${ }^{\star}$ Corresponding author, E-mail: ineta.samsone@silava.lv
}

\begin{abstract}
Tissue recalcitrance remains a major problem limiting woody plant propagation using in vitro biotechnology methods. Increased generation of reactive oxygen species and high phenol concentration in woody tissues are considered as the main reasons for tissue recalcitrance in tissue culture. In this study, oxidative enzyme activity and total phenolic concentration were analyzed in vitro in both rejuvenated and mature shoots of birch. The effect of two factors - subculture time and medium sucrose concentration - on peroxidase and polyphenol oxidase activity, and total phenolic concentration in rejuvenated shoots were determined as possible rejuvenationaffecting factors. The results showed that mature shoots had increased peroxidase and polyphenol oxidase activity in shoot apices and stems but higher phenolic concentration in leaves as compared to rejuvenated shoots. Prolonged subculture time had significant effect on peroxidase activity and polyphenol oxidase activity in shoot apices, and thus this factor did not affect maturation. However, high sucrose concentration significantly increased total phenolic concentration in leaves and polyphenol oxidase activity in all plant parts, thus enhancing shoot maturation and recalcitrance in vitro.
\end{abstract}

Key words: Betula pendula, phenolics, peroxidase, polyphenol oxidase, rejuvenation, sucrose.

\section{Introduction}

Micropropagation is an effective vegetative technique to obtain clonal material of desired woody plant varieties or superior genotypes. Tissue recalcitrance is a major factor limiting mature woody plant micropropagation and is described as inability of tissues to respond to in vitro stimulus to reach morphogenic competence and totipotent capacity (Benson 2000). Recalcitrance is attained gradually as a tree ages and shifts to its mature phase, and is encompassed with other significant physiological changes, like seasonal shoot growth pattern, reduced growth and rooting capacity as well as production of secondary metabolites (McCown 2000). The level of recalcitrance for a particular explant is influenced by both endogenous and exogenous factors (Bonga et al. 2010).

One of the main physiological factors affecting tissue culture recalcitrance is oxidative stress (Benson 2000). Mature woody plants usually have elevated oxidative enzyme activity and contain higher amounts of phenolic compounds as compared to juvenile plants of the same species (Warrier et al. 2013). When such tissues are introduced in tissue culture, wounding and other stresses during cultivation (osmotic shock, nitrogen toxicity, altered gas composition, hormonal imbalance) cause rapid production of reactive oxygen species, as a result leading to disorganization of cell structures and oxidation of phenolic compounds, appearing as tissue browning, necrosis and death (Benson 2000).

Elevated oxidative enzyme activity and higher phenolic concentration has been shown to be correlated with low tissue responsiveness in tissue culture (Laukkanen et al. 1999). Despite recent advances in elucidation of the physiological and molecular basis of woody plant development and in vitro regeneration, an exact mechanism of tissue recalcitrance in vitro and ways to overcome it remains poorly understood (Díaz-Sala 2016). Therefore, the aim of this study was to determine oxidative enzyme activity and total phenolic concentration in rejuvenated and mature recalcitrant birch shoots in tissue culture, and to determine the effect of two in vitro factors - subculture time and sucrose concentration - on peroxidase, polyphenol oxidase activity and total phenolic concentration in rejuvenated shoots.

\section{Materials and methods}

\section{Plant material}

Buds from 10 different clones of mature approximately 20-year-old birch (Betula pendula Roth) elite trees grown in a progeny trial in the region of Kegums in Latvia were selected and initiated in vitro to obtain shoot cultures. After six months three clones showing both rejuvenated shoots (characterized with high proliferation rate and high rooting 
capacity) and mature shoots (characterized with low proliferation rate and zero rooting capacity) were selected for further experiments. Three experimental sets were used, with approximately 30 rejuvenated and 30 mature shoots per each experiment.

(1) Determination of oxidative enzyme activity and total phenolic concentration in rejuvenated and mature birch in vitro shoots. Shoots from each type were cultured on Woody Plant Medium (Lloyd, McCown 1980) supplemented with $0.2 \mathrm{mg} \mathrm{L}^{-1}$ zeatin, $20 \mathrm{~g} \mathrm{~L}^{-1}$ sucrose and $6 \mathrm{~g} \mathrm{~L}^{-1}$ agar. $\mathrm{pH}$ of the medium was adjusted to 5.8 before autoclaving for 15 $\min \left(110 \mathrm{kPa}, 121^{\circ} \mathrm{C}\right)$. Cultures were kept at $25 \pm 3{ }^{\circ} \mathrm{C}$, with a $16 / 8 \mathrm{~h}$ light/dark period, illumination provided by cool-white fluorescent lamps (photosynthetically active radiation with a photon flux density 140 to $160 \mu \mathrm{mol} \mathrm{m}{ }^{-2}$ $\mathrm{s}^{-1}$ ). After four weeks shoots were collected for enzyme and total phenolic concentration assay.

(2) The effect of subculture time on oxidative enzyme activity. Rejuvenated shoots were cultured as previously described. During cultivation, shoots were collected for enzyme assay after three subculture time intervals: one week, eight weeks and 11 weeks.

(3) The effect of elevated sucrose concentration on oxidative enzyme activity and total phenol content. Rejuvenated shoots were kept on sucrose concentration 20 and $50 \mathrm{mg} \mathrm{L}^{-1}$ for two weeks, part of shoots were used for enzyme extraction and the remaining were cultured for two more weeks with subsequent total phenolic extraction.

\section{Guaiacol peroxidase and polyphenol oxidase assay}

Enzyme assay was performed by a modified protocol from Andersone and Ievinsh (2002). Shoots were divided into leaves, shoot apices and stems. Samples $(250 \mathrm{mg})$ from each plant part were ground together with $2.5 \mathrm{~mL} 25 \mathrm{mmol} \mathrm{L}^{-1}$ HEPES/KOH buffer ( $\mathrm{pH} 7.2$ ), containing $1 \mathrm{mmol} \mathrm{L}^{-1}$ EDTA and $1 \%(\mathrm{w} / \mathrm{v})$ polyvinylpolypyrrolidone. Extract was kept $15 \mathrm{~min}$ at $4{ }^{\circ} \mathrm{C}$, followed by centrifugation at $13000 \mathrm{rpm}$ for $20 \mathrm{~min}$. Guaiacol peroxidase and polyphenoloxidase activity was measured spectrophotometrically using a Lambda 25 UV/Vis Spectrometer (PerkinElmer). For peroxidase, the reaction mixture contained $2 \mathrm{~mL} 50 \mathrm{mmol}$ $\mathrm{L}^{-1}$ sodium phosphate $\left(\mathrm{NaH}_{2} \mathrm{PO}_{4} / \mathrm{Na}_{2} \mathrm{HPO}_{4}\right)$ buffer $(\mathrm{pH} 7.0)$ with $10 \mathrm{mmol} \mathrm{L}^{-1}$ guaiacol, $0.5 \mathrm{~mL} 3 \mathrm{mmol} \mathrm{L}^{-1} \mathrm{H}_{2} \mathrm{O}_{2}$ and
$0.02 \mathrm{~mL}$ enzyme extract. Activity was measured at $470 \mathrm{~nm}$. For polyphenol oxidase, the reaction mixture contained 3 $\mathrm{mL} 20 \mathrm{mmol} \mathrm{L}^{-1}$ sodium phosphate buffer ( $\mathrm{pH} 7.0$ ) with 25 $\mathrm{mmol} \mathrm{L}^{-1}$ pyrocathecol and $0.1 \mathrm{~mL}$ enzyme extract. Activity was measured at $410 \mathrm{~nm}$. Three biological and three chemical replicates were performed for each treatment. Mean and standard deviation were calculated.

\section{Total phenol concentration assay}

Total phenolic concentration assay was performed according to modified protocol from Harald et al. (2012). Leaves were dried at room temperature and grated in fine powder. Samples $(250 \mathrm{mg})$ of plant material were mixed with $50 \mu \mathrm{L} 50 \%$ ethanol and centrifuged at $5000 \mathrm{rpm}$ for 10 $\mathrm{min}$. The supernatant was diluted to $6 \%$ using $50 \%$ ethanol. Gallic acid was used as a standard at 0.025 to $0.2 \mathrm{mg} \mathrm{mL}^{-1}$ to produce a calibration curve $\left(R^{2}=0.996\right)$. In each cell of a 96-well microplate, $75 \mu \mathrm{L} \mathrm{H}_{2} \mathrm{O}, 25 \mu \mathrm{L} 6 \%$ extract or standard and $25 \mu \mathrm{L} 50 \%$ Folin-Ciocalteu reagent were added. Solutions were mixed and left for $6 \mathrm{~min}$. Then $100 \mu \mathrm{L} 7 \%$ $\mathrm{Na}_{2} \mathrm{CO}_{3}$ was added to each well, mixed again and left in the dark for $90 \mathrm{~min}$. The absorbance at $620 \mathrm{~nm}$ was measured with a Biochrom Asys Expert Plus spectrophotometric microplate reader (Biochrom). Each standard and sample solution was analysed in triplicate, and assayed against a sample control (50\% ethanol). Total phenolic concentration was expressed as gallic acid equivalent (GAE; $\mathrm{mg} \mathrm{g}^{-1}$ ).

\section{Results}

Significant differences in peroxidase and polyphenol oxidase activity were observed between different plant parts from rejuvenated and mature shoots (Fig. 1). The lowest enzyme activity for both rejuvenated and mature shoots was observed in leaves followed by shoot apices and stems, except for peroxidase activity in shoot apices in mature shoots, which was higher than in stems. Both peroxidase and polyphenol oxidase activity was about 1.6 times lower in mature shoot leaves as compared to rejuvenated shoot leaves, whereas in shoot apices and stems the activity was higher in mature shoots by about 1.3 times for peroxidase and 1.8 times for polyphenol oxidase. In mature shoots, differences in polyphenol oxidase activity were more
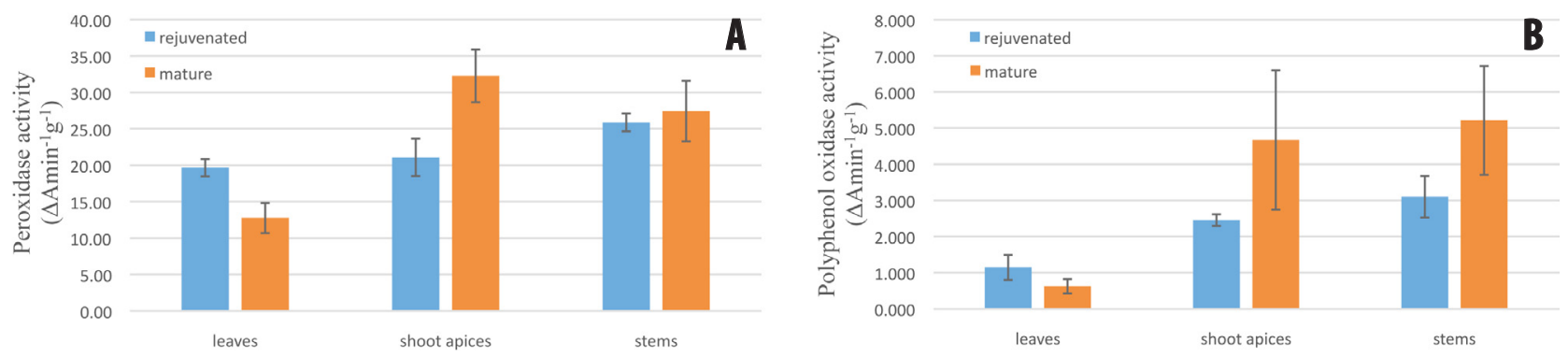

Fig. 1. Peroxidase (A) and polyphenol oxidase (B) activity in different shoot structures of mature and rejuvenated Betula pendula shoots. Mean and standard deviation is shown. 


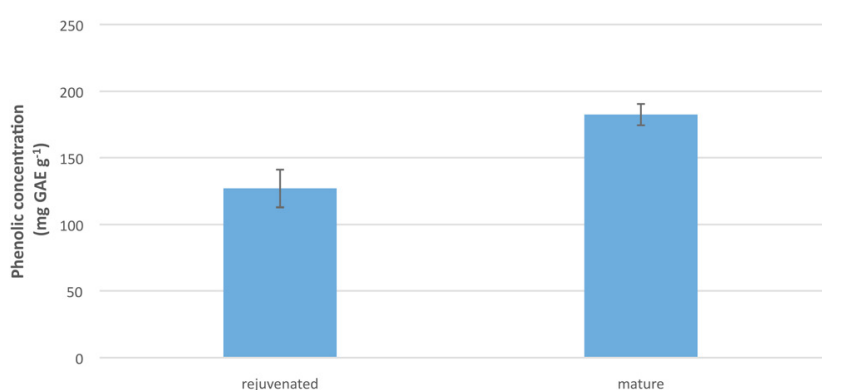

Fig. 2. Total phenolic concentration in leaves of mature and rejuvenated Betula pendula shoots. Mean and standard deviation is shown.

pronounced in comparison to peroxidase activity. Results for total phenolic analysis showed that mature shoots had elevated levels of phenolic compounds, having 1.4 times higher phenolic concentration in leaves as compared to leaves of rejuvenated shoots (Fig. 2).

Evaluating the effect of subculture time on enzyme activity, it was observed that peroxidase activity was relatively stable in time in all shoot structures during cultivation, except peroxidase activity in shoot apices, which was about three times higher after 11 weeks as compared to activity after one or eight weeks of subculturing (Fig. 3). In contrast, polyphenol oxidase activity was significantly higher in leaves and stems after one week of subculturing, but was lower and remained relatively stable after eight and 11 weeks.

After two weeks of cultivation in the presence of elevated sucrose concentration in the medium $\left(50 \mathrm{~g} \mathrm{~L}^{-1}\right)$, contrasting effect on peroxidase and polyphenol oxidase activity was observed (Fig. 4). Peroxidase activity decreased in all structures in the presence of elevated sucrose, with the greatest reduction in leaves and shoot apices, where the activity was about 1.4 times lower than at optimal sucrose concentration. The opposite effect was observed for polyphenol oxidase, where the activity increased in all structures by about 1.3 times. There was also a significant increase in total phenolic concentration in shoots grown on elevated sucrose, which was 2.5 times higher than at optimal sucrose concentration (Fig. 5).
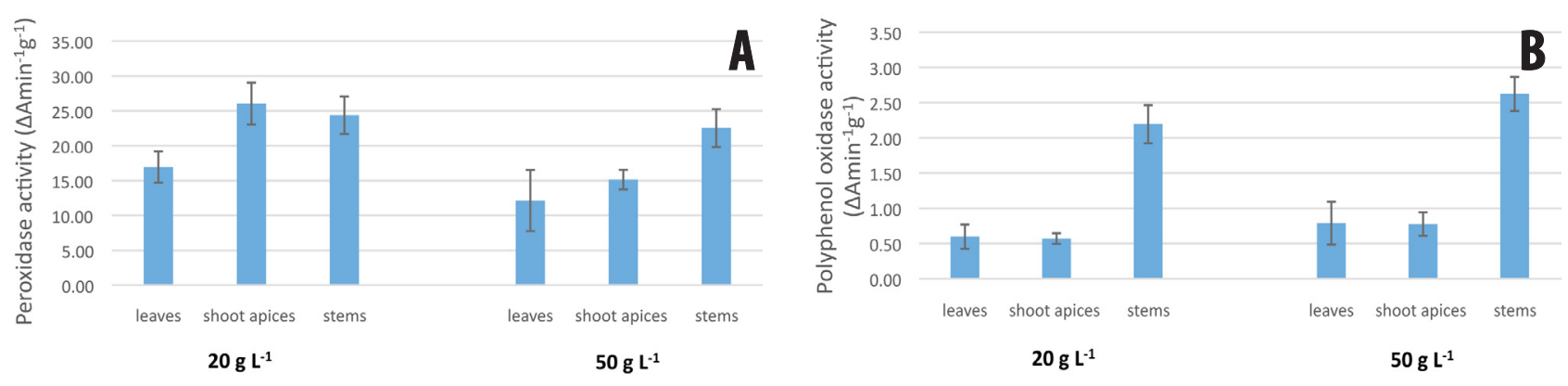

Fig. 4. Peroxidase (A) and polyphenol oxidase (B) activity in different shoot structures in rejuvenated Betula pendula shoots cultured on different sucrose concentration. Mean and standard deviation is shown.

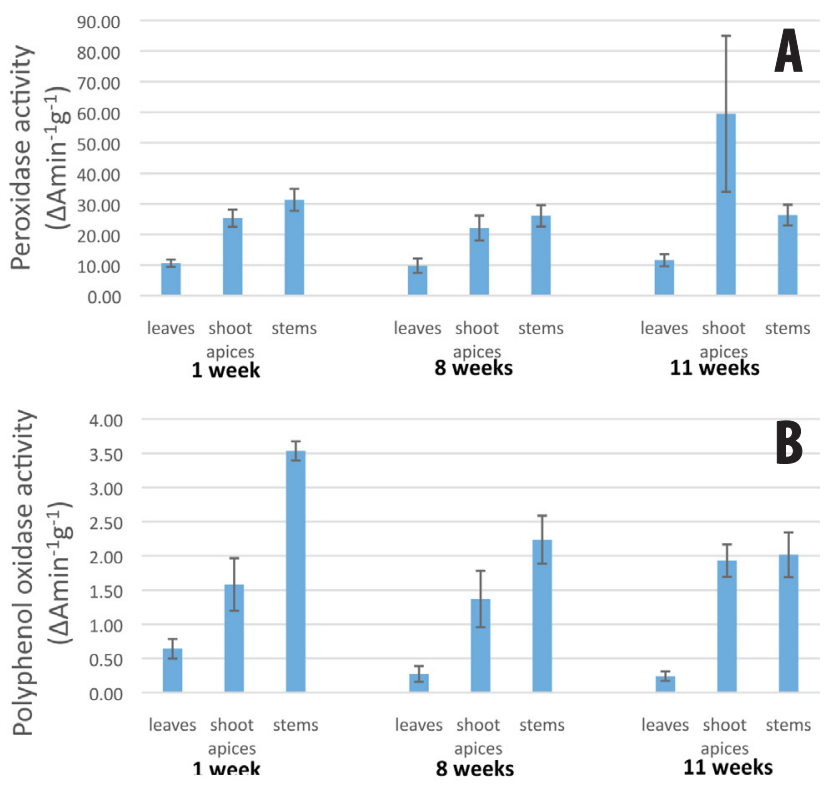

Fig. 3. Peroxidase (A) and polyphenol oxidase (B) activity in different shoot structures in rejuvenated Betula pendula shoots at different subculture times. Mean and standard deviation is shown.

\section{Discussion}

A variety of different potential explanations for recalcitrance have been published, suggesting that several mechanisms may operate independently, including nutritional and hormonal state, oxidative enzyme activity and genetic and epigenetic factors (Díaz-Sala 2016). In this study we observed elevated peroxidase and polyphenol oxidase activity in mature recalcitrant birch shoots apices and stems as compared to rejuvenated shoots. Oxidative enzyme activity has been shown to be elevated in mature plants and it usually correlated with low tissue responsiveness in tissue culture (Warrier et al. 2013). For example, Andersone and Ievinsh (2002) observed no tissue morphogenesis of Pinus sylvestris buds, when peroxidase and polyphenol oxidase levels were higher, compared to increased morphogenesis, when oxidative enzyme activity was lower and remained stable.

High peroxidase activity in mature plants can be 


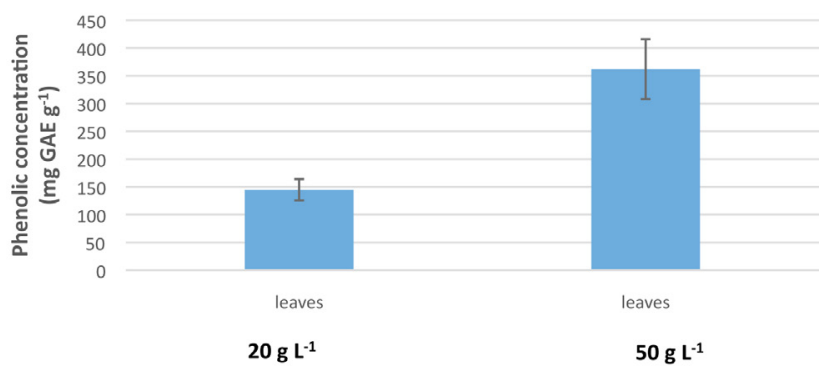

Fig. 5. Total phenolic concentration in leaves of rejuvenated Betula pendula shoots cultured on different sucrose concentration. Mean and standard deviation is shown.

attributed to its role in reduction of $\mathrm{H}_{2} \mathrm{O}_{2}$ and lignification processes (Hiraga et al.2001). This indicates that the higher peroxidase activity in stems and shoot apices observed in this experiment as compared to leaves could also be attributed to increased lignification in these parts. Lower oxidative enzyme activity in mature shoot leaves could be reason of ageing of leaves and tissue deterioration. $\mathrm{H}_{2} \mathrm{O}_{2}$ is the most abundant reactive oxygen species in plants and its concentration increases dramatically during the adult phase, as does the concentrations of its scavengers (Du et al.2015). It is known that redox homeostasis, which is maintained by the precise generation and scavenging of $\mathrm{H}_{2} \mathrm{O}_{2}$ and other types of reactive oxygen species, interacts with the phytohormone signalling network, thus controlling many aspects of plant growth, differentiation, development and environmental responses (Considine, Foyer 2014). $\mathrm{H}_{2} \mathrm{O}_{2}$ is a known inducer of gene expression, and recent studies indicate its role in the molecular mechanism of phase change through modulating the expression of phase change master regulator microRNA miR156/157 (Wu et al. 2009). When $\mathrm{H}_{2} \mathrm{O}_{2}$ or glutathione concentration of suspension cells was altered by specific treatment, the levels of gene MdMIR156a5 and MdMIR156a12 transcripts as well as the mature miR156 expression level changed accordingly (Jia et al. 2017).

Polyphenol oxidase activity is also usually elevated in mature tissues and is often observed together with elevated phenolic concentration (Warrier et al. 2013). Plants synthesize phenolics constitutively or as a response to stress. Wounding and other stresses during in vitro initiation cause disorganization of tissue or cell structures, resulting in mixing of phenolics, enzymes, and their cosubstrates $\mathrm{O}_{2}$ or $\mathrm{H}_{2} \mathrm{O}_{2}$, leading to oxidation of phenolic compounds, browning and necrosis (Benson 2002). Both peroxidase and polyphenol oxidase are involved in this process, and thus their activity is usually elevated in tissues rich in phenolics (Vondráková et al. 2016).

In this study polyphenol oxidase activity was higher in mature tissues and showed similar pattern to peroxidase, only the differences between juvenile and mature parts were more pronounced than for peroxidase, making it a better marker for shoot mature state determination. We also observed elevated polyphenol oxidase activity in mature shoots together with higher phenolic concentration, which perhaps caused their recalcitrance. Woody plants, especially Quercus, Pinus and Betula, are rich in tannins that often leads to tissue culture browning and are considered as a major factor for the recalcitrance in vitro (Vondráková et al. 2016).

During in vitro cultivation, plant tissues are subjected not only to higher oxidative metabolism already present in mature tissues, but to all kinds of other stresses during cultivation, like osmotic shock (resulting from high amount of sucrose), nitrogen toxicity, hormonal imbalance and gas toxicities (high concentration ethylene) etc., that can lead to oxidative stress (Desjardins et al. 2009). For example, long subculture intervals can enhance phenolic synthesis and elevate peroxidase activity (Abohatem et al. 2011). In this study we observed increased peroxidase activity in rejuvenated shoot apices after 11 weeks of cultivation, whereas polyphenol oxidase activity showed only a little increase. Instead, polyphenol oxidase increased after one week of cultivation, indicating wound-induced phenolic synthesis. Therefore, the increased peroxidase activity in shoot apices after 11 weeks could be due to mineral deficiency (caused by prolonged time without transfer to new medium) rather than to maturation. Therefore, the prolonged culture time is not likely to cause maturation and recalcitrance in birch shoots.

Sucrose is known to induce major stress responses in vitro, including interaction with hormone signalling pathways, binding to hexokinase that activates a number of stress adaptation responses, inhibition of the photosynthetic electron transport chain and osmotic stress (Desjardins et al. 2009). Sucrose is also known as one of the main factors inducing maturation in plants. The glucose signalling protein in Arabidopsis thaliana showed close relationship with the expression of two genes MIR1256A and MIR156C (Yu et al. 2013). In this study elevated sucrose concentration caused decrease in peroxidase activity in all plant parts. Various abiotic stress factors usually cause increase of peroxidase activity, but contradictory results also exist, where decrease of peroxidase activity is observed during abiotic stress (van Doorn, Kesta 2014). A similar mechanism might have contributed to the decrease of peroxidase activity found in this study. We observed significant increase of phenolic concentration in the presence of elevated sucrose, which may be associated with increased polyphenol oxidase activity. During plant growth sucrose alters the $\mathrm{C}$ and $\mathrm{N}$ ratio in plants, thus coordinating many processes of plant development including maturation and synthesis of secondary metabolites (Zheng 2009). Phenolic synthesis requires carbohydrates, which explains the sharp increase in phenolic concentration in the presence of high sucrose observed in this experiment. A similar effect was also observed in Camellia sinensis plants in vitro (Qian et al. 2018). Therefore, sucrose might play a role in birch in vitro 
shoot recalcitrance and lowered sucrose concentration might be beneficial during rejuvenation.

In conclusion, peroxidase and polyphenol oxidase activity, as well as total phenolic concentration can be used as indicators for birch in vitro shoot rejuvenation status, indicating increased peroxidase and polyphenol oxidase activity and higher phenolic concentration in mature recalcitrant shoots compared to rejuvenated shoots. In vitro factors, like prolonged subculture time, are not likely to cause maturation. However, high sucrose concentration might be involved in maturation, by enhancing phenolic synthesis and elevating polyphenol oxidase activity.

\section{References}

Abohatem M., Zouine J., Hadrami I.E. 2011. Low concentrations of BAP and high rate of subcultures improve the establishment and multiplication of somatic embryos in date palm suspension cultures by limiting oxidative browning associated with high levels of total phenols and peroxidase activities. Sci. Horticult. 130: 344-348.

Andersone U., Ievinsh G. 2002. Changes of morphogenic competence in mature Pinus sylvestris L. buds in vitro. Ann. Bot. 90: 293-298.

Benson E.E. 2000. Do free radicals have a role in plant tissue culture recalcitrance? In Vitro Cell. Dev. Biol. Plant 36: 163170.

Bonga J.M., Klimaszewska K.K., von Aderkas P. 2010. Recalcitrance in clonal propagation, in particular of conifers. Plant Cell Tissue Organ Cult. 100: 241-254.

Considine M. J., Foyer C. H. 2014. Redox regulation of plant development. Antioxid. Redox Signal. 21: 1305-1326.

Desjardins Y., Dubuc J.F., Badr A. 2009. In vitro culture of plants: a stressful activity! Acta Horticult. 812: 29-50.

Díaz-Sala C. 2016. Physiological, cellular, molecular and genomic analysis of the effect of maturation on propagation capacity. In: Park Y.S., Bonga J., Moon H.K. (eds) Vegetative Propagation of Forest Trees. Online Edition. National Institute of Forest Science, pp. 97-120.

Du Z., Jia X.L., Wang Y., Wu T., Han Z.H., Zhang X.Z. 2015. Redox homeostasis and reactive oxygen species scavengers shift during ontogenetic phase changes in apple. Plant Sci. 236:
283-294.

Hiraga. S., Sasaki K., Ito H., Ohashi Y., Matsui H. 2001. A large family of class III plant peroxidases. Plant Cell Physiol. 42: 462-468.

Jia X.L., Chen Y.K., Xu X.Z., Shen F., Zheng Q.B., Du Z., Wang Y, Wu T, Xu X.F, Han Z.H., Zhang X.Z. 2017. MiR156 switches on vegetative phase change under the regulation of redox signals in apple seedlings. Sci. Rep. 7: 14223.

Laukkanen H., Häggman H., Kontunen-Soppela S., Hohtola A. 1999. Tissue browning of in vitro cultures of Scots pine: Role of peroxidase and polyphenol oxidase. Physiol. Plant. 106: 337-343.

Lloyd G., McCown B. 1980. Commercially-feasible micropropagation of mountain laurel, Kalmia latifolia, by use of shoot-tip culture. Combined Proceedings of the International Plant Propagators Society 30: 421-427.

McCown B.H. 2000. Recalitrance of woody and herbaceous perennial plants: Dealing with genetic predeterminism. In Vitro Cell. Dev. Biol. Plant 36: 149-154.

Qian Y., Zhang S., Yao S, Xia J., Li Y., Dai X.,Wang W., Jiang X., Liu Y., Li M., Gao L., Xia T. 2018. Effects of in vitro sucrose on quality components of tea plants (Camellia sinensis) based on transcriptomic and metabolic analysis. BMC Plant Biol. 18: 121.

Van Doorn W.G., Kesta S. 2014. Cross reactivity between ascorbate peroxidase and phenol (guaiacol) peroxidase. Postharv. Biol. Technol. 95: 64-69.

Vondráková Z., Krajňáková J., Fischerová L. Vágner M. Eliášová K. 2016. Physiology and role of plant growth regulators in somatic embryogenesis. In: Park Y.S., Bonga J., Moon H.K. (eds) Vegetative propagation of Forest Trees. Online Edition. National Institute of Forest Science, pp. 123-169.

Warrier K.C.S., Anandalakshmi R., Warrier R.R., Singh B.G. 2013. Differential expression of biochemicals with reference to the degree of juvenility in Casuarina equisetifolia. Int. J. Adv. Life Sci. 6: 216-224.

Wu G., Park M.Y., Conway S.R., Wang J.W., Weigel D., Poethig R.S. 2009. The sequential action of miR156 and miR172 regulates developmental timing in Arabidopsis. Cell 138: 750-759.

Yu S., Cao L., Zhou C.M., Zhang T.Q., Lian H., Sun Y., Wu J., Huang J., Wang G., Wang J.W. 2013. Sugar is an endogenous cue for juvenile-to-adult phase transition in plants. eLife 2: e00269.

Zheng Z.L. 2009. Carbon and nitrogen nutrient balance signaling in plants. Plant Signal. Behav. 4: 584-591. 